Bauwelt Fundamente 169

Herausgegeben von

Elisabeth Blum

Jesko Fezer

Günther Fischer

Angelika Schnell 



\section{Stephan Trüby}

Rechte Räume

Politische Essays und Gespräche 
Die Reihe Bauwelt Fundamente wurde von Ulrich Conrads 1963 gegründet und seit Anfang der 1980erJahre gemeinsam mit Peter Neitzke herausgegeben. Verantwortliche Herausgeberin für diesen Band: Elisabeth Blum

Gestaltung der Reihe seit 2017: Matthias Görlich

Vordere Umschlagseite: Kontinuität der Reichsidee als rechte Obsession - das Steinbild des erwachenden Barbarossa, von 1155 bis 1190 Kaiser des römisch-deutschen Reiches, am zwischen 1892 und 1896 nach Plänen von Bruno Schmitz gegen den „inneren Feind“ der Sozialdemokratie errichtete Kyffhäuserdenkmal in Thüringen (Foto: Stephan Trüby, 2018).

Hintere Umschlagseite: Frisch gestrichen, aber noch im Bau - der rekonstruierte Krönungsweg der Neuen Frankfurter Altstadt (Stand: 30. November 2017), den zwischen 1562 und 1792 zehn römisch-deutsche Könige und Kaiser gingen (Foto: Stephan Trüby).

Library of Congress Control Number: 2020947588

Bibliografische Information der Deutschen Nationalbibliothek

Die Deutsche Nationalbibliothek verzeichnet diese Publikation in der Deutschen Nationalbibliografie; detaillierte bibliografische Daten sind im Internet über http://dnb.dnb.de abrufbar. Dieses Werk ist urheberrechtlich geschützt. Die dadurch begründeten Rechte, insbesondere die der Übersetzung, des Nachdrucks, des Vortrags, der Entnahme von Abbildungen und Tabellen, der Funksendung, der Mikroverfilmung oder der Vervielfältigung auf anderen Wegen und der Speicherung in Datenverarbeitungsanlagen, bleiben, auch bei nur auszugsweiser Verwertung, vorbehalten. Eine Vervielfältigung dieses Werkes oder von Teilen dieses Werkes ist auch im Einzelfall nur in den Grenzen der gesetzlichen Bestimmungen des Urheberrechtsgesetzes in der jeweils geltenden Fassung zulässig. Sie ist grundsätzlich vergütungspflichtig. Zuwiderhandlungen unterliegen den Strafbestimmungen des Urheberrechts.
Dieses Buch ist auch als E-Book (ISBN 978-3-03562241-6) erschienen.

Der Vertrieb über den Buchhandel erfolgt ausschließlich über den Birkhäuser Verlag.

(C) 2020 Birkhäuser Verlag GmbH, Basel, Postfach 44, 4009 Basel, Schweiz, ein Unternehmen von Walter de Gruyter GmbH, Berlin/Boston; und Bauverlag BV GmbH, Gütersloh, Berlin

Gedruckt auf säurefreiem Papier, hergestellt aus chlorfrei gebleichtem Zellstoff. TCF $\infty$

\section{bau || | verlag}

Printed in Germany

ISBN 978-3-0356-2240-9

\section{1}

www.birkhauser.com

Publiziert mit der freundlichen Unterstützung von:

\section{Universität Stuttgart}

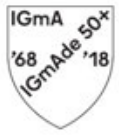

